\title{
A Review of the Petroleum Hydrocarbons Contamination of Soil, Water and Air and the Available Remediation Techniques, Taking into Consideration the Sustainable Development Goals
}

\author{
Adeoye Ademola Elijah
}

Department of Chemistry, Federal University of Technology, Akure, Ondo State, Nigeria

e-mail: ademolaadeoye61@gmail.com

\begin{abstract}
The emergence of several industrial activities has arguably led to hydrocarbon contamination of all aspects of the environment. The resultant effect of the increased dependence on crude oil is the hydrocarbon pollution via the exploration, transport and waste disposal. Crude oil is a complex mixture of aliphatic, aromatic and heterocyclic compounds. The impact of the crude oil spills, pesticides, fossil fuels and other organic pollutants, which majorly contains these hydrocarbons is that the natural heavy metal content of the soil is drastically rising, resulting in high concentration of heavy metals, thereby limiting the microbe's activity, rendering it unsuitable for degradation and reduced effectiveness. This menace has hereby brought the dire need for adequate environmental remediation technique, putting into consideration the achievement of the Sustainable Development Goals (SDGs'). Variety of techniques exist for remediation depending on the media (e.g. air, water, or soil) and contaminant (e.g. heavy metals, PCB etc.). Some of the techniques adopted in the last several decades are physical/mechanical, chemical or biochemical remediation methods.
\end{abstract}

\section{Introduction}

Although, there are recent advancements in the use of renewable energies, the harnessing of crude oil is still a necessity for several countries. However, the incidence of facilities sabotage (theft and bunkering), operational failures (corrosion of pipeline, human error and equipment failure), pipeline vandalization and leakage, accidental discharges as well as the inappropriate handling and disposal of petroleum wastes has Received: November 13, 2021; Accepted: December 28, 2021

Keywords and phrases: hydrocarbon; aromatic; metals; contaminants; pesticides; petroleum; remediation.

Copyright (C) 2022 Adeoye Ademola Elijah. This is an open access article distributed under the Creative Commons Attribution License, which permits unrestricted use, distribution, and reproduction in any medium, provided the original work is properly cited. 
been of great harm to environmental safety, protection and sustainability [1,2]. Contamination of hydrocarbon occurs due to petroleum, pesticides, fossil fuel, and other toxic organic substances. However, of all these sources, contamination caused by petroleum hydrocarbon, is most common due to its extensive use and its related accidental spills and waste disposal process. Petroleum consists of a large range of high and low molecular weight hydrocarbons. These complex mixtures consist of saturated and branched alkanes, alkenes, homo and heterocyclic napthtenes, aromatics consisting of heteroatoms such as heavy metal complexes, N, S and O, hydrocarbons consisting of different functional groups such as ethers, carboxylic acids, asphaltenes, resins and naphteno-aromatics. Based on the hydrocarbon composition of the products of the fractrional distillation of crude oil, light end fractions e.g. naphta, diesel, kerosene etc. have a lower percentage of aromatic compounds and lower molecular weight saturated and unsaturated hydrocarbons while the heavy end fractions e.g. asphaltenes and lube oil consists of higher percentage of aromatic compounds and higher molecular weight saturated and unsaturated hydrocarbons and organometallics [3].

Concentration of heavy metal is on a steady rise in the soil due to these human activities. There is a large impact of higher heavy metal and metalloid concentration in some areas [4]. Crude oil and petroleum products form a waterproof film on water that prevents the oxygen exchange between environment and water causing damages to plants, animals, and human beings.

\section{Common Pollutants in Water, Air and Soil}

\section{Hydrocarbon pollution}

This is caused mainly by accidents on oil platforms and ships used for hydrocarbon transportation but also by discharging water into the sea which is used to wash tanks of tanker vessels. Crude oil and petroleum products form a waterproof film on water that prevents the oxygen exchange between environment and water causing damages to plants, animals, and human beings [2].

\section{Organic pollutants}

Major sources which are responsible for organic contaminants are anthropogenic activities including the use of fuels, solvents, and pesticides. Various organic compounds are harmful and are related to health concerns globally. Diverse sources are responsible for the generation of hydrocarbons in sediments which are categorized below $[5,6]$ : 
- Anthropogenic sources

- Petroleum inputs

- Partial burning of fuels

- Fires of forest and grass

- Biosynthesis of hydrocarbons by marine or terrestrial organisms

- Diffusing from the petroleum source rocks, reservoirs, or mantle

Organic pollutant is responsible for environmental and health-related problems

\section{Polycyclic aromatic hydrocarbons (PAHs)}

PAHs are considered to be ubiquitous contaminants. There are 100 diverse compounds of polycyclic aromatic hydrocarbons present. PAHs are seldom used for the industrial purpose, but only few are used for the manufacturing of pesticides, dyes and plastics and for the production of medicines. Polycyclic aromatic hydrocarbons are produced on partial burning of organic matters [7]. PAHs due to carcinogenic and mutagenic nature are highly poisonous to organisms. The degradation of PAHs is predominantly slow with high molecular weights because due to low hydrophobicity and water solubility it has a tendency to accumulate in sediments [8].

\section{Polychlorinated biphenyls (PCBs)}

Polychlorinated biphenyls (PCBs) due to carcinogenicity, toxicity, and slow biodegradation in the nature are well thought-out to be the worst pollutants [9] of commercial PCBs of about hundreds of thousands of metric tons are persevere in aquatic sediments [10]. In adhesives and lubricants, dielectric fluids in flame retardants, transformers, hydraulic fluids, and plasticizers, PCBs are widely used. PCBs are released from disposal and spillage [11].

\section{Polychlorinated dibenzo-p-dioxins and dibenzofurans (PCDD/Fs)}

Polychlorinated dibenzo-p-dioxins and dibenzofurans (PCDD/Fs) are still present in deep sediment layers which are deposited decades ago. Toward biotic and abiotic degradation processes, PCDD/Fs are often well-thought-out to be recalcitrant [12]. $\mathrm{PCDD} / \mathrm{Fs}$ are the most notorious pollutants present in nature [13]. 


\section{Inorganic pollutants}

Human sources are mainly responsible for the heavy metal contamination, but contamination due to natural and biological processes are also common. Cellular binding sites of microbes are responsible for the absorption of heavy metals. By various mechanisms, heavy metals can be complexed with extracellular polymers of microbes. Organic contaminants can be mineralized by these microorganisms and convert into metabolic intermediates which can be utilized as primary substrates for growth of the cell. Heavy metals can be eliminated from the metal-polluted soil by microbes which can change the heavy metal oxidation state by immobilizing them [14]. Research on bioremediation of heavy metals by microbes is on the increase of recent.

\section{Sources and Effects of Hydrocarbon-Contaminated Wastewater Effluents}

Numerous sources such as pesticides, petroleum, or different harmful organic substances which are discharged into the water streams as effluents are responsible for the hydrocarbon pollution into the wastewater. Water contaminated with hydrocarbons is known to be carcinogenic, neurotoxin, and mutagenic to flora and fauna [15]. Increased use of vehicles and automobiles leads to increase in utilization of automobile oil, which is the major cause of hydrocarbon contamination in water. This type of contamination occurs when oil from the car drops onto the ground and leaks; it could be washed into water streams by runoffs [17].

Pesticides are another source of hydrocarbon contamination in water. Pesticides include herbicides, fungicides, and insecticides. Only small amount of pesticide is able to achieve the target, while the major proportion stays in the soil, and it can be washed away by the rain in the water stream [18]. Herbicides, out of all the pesticides, are most hazardous because it is directly applied on the soil in order to kill the weed and can be washed away during rainfall into the water streams.

One of the main sources of hydrocarbon pollution is the discharge of urban storm water [19]. In urban communities, car parks and roads are frequently polluted by gasoline and oil from the vehicles, and during rainfall, these pollutants are washed into water streams and hence can contaminate them [19]. Wastewater contaminated by hydrocarbons has an adverse effect in nature, animals, human beings, and plants. Lack of oxygen, decrease in crop yield, and effects on aquatic plants are various effects of hydrocarbon contamination in nature. There would be decrease in the crop yield and available food for household due to inappropriate crop's growth when the farmland is 
irrigated by water contaminated with hydrocarbon [20,21]. Soil fertility can be decreased to an extent due to the presence of oil in water due to the reason that most of the vital nutrients are no longer accessible for crop consumption which results in the decrease of the crop yield. The reduction in the yield of crop results in the decrease of the farmer's earnings [22,23]. Oxygen shortage is another environmental effect of hydrocarbon contamination. The main source of oxygen in nature is the economic trees which rely on rainfall or on the water steams for their growth. Oil spills can inhibit root penetration due to hydrocarbons which can block the pores of the soil, thereby removing water and air [24]. This results in the death of such plant or distortion in the growth and hence causes oxygen shortage for human utilization [25]. Hydrocarbon contamination in water avoids the penetration of light into the water and the exchange of gases for consumption by aquatic plants. This leads to the death of the plant because plant becomes incapable to photosynthesize and hence can affect the food chain. Plants consume the pollutants from the contaminated water which can be passed to humans and animals through the food chain [26].

Polycyclic hydrocarbons are toxic and found to have serious effects on human beings. The immune system, liver, respiratory system, reproductive system, circulatory system, kidney, etc. are the organs which are affected due to the hydrocarbon ingestion [21]. Individual's susceptibility and level of exposure are the factors on which the degree of damage depends [16]. Cancer risk and hormonal problems that can disturb developmental and reproductive processes are the other effects of effluents polluted by hydrocarbons on human beings [27].

Discharge of wastewater contaminated with hydrocarbon into the water streams poses risk to animals through absorption, breathing, and ingestion. Sea birds are the most exposed to the hydrocarbon pollutant because it spends majority of its time near the water bodies [28]. There is unusual decrease in the temperature due to the destruction of the protective layer of the feathers in sea birds as a result of the presence of oil in water [29].

\section{Sustainable Development Goals}

The Sustainable Development Goals (SDGs) or Global Goals are a collection of 17 interlinked global goals designed to be a "blueprint to achieve a better and more sustainable future for all" [30]. The SDGs were set up in 2015 by the United Nations General Assembly and are intended to be achieved by the year 2030. They are included in a UN Resolution called the 2030 Agenda or what is colloquially known as Agenda 2030 
[31]. The SDGs were developed in the Post-2015 Development Agenda as the future global development framework to succeed the Millennium Development Goals which ended in 2015.

The 17 SDGs are: (1) No Poverty, (2) Zero Hunger, (3) Good Health and Well-being, (4) Quality Education, (5) Gender Equality, (6) Clean Water and Sanitation, (7) Affordable and Clean Energy, (8) Decent Work and Economic Growth, (9) Industry, Innovation and Infrastructure, (10) Reducing Inequality, (11) Sustainable Cities and Communities, (12) Responsible Consumption and Production, (13) Climate Action, (14) Life Below Water, (15) Life On Land, (16) Peace, Justice, and Strong Institutions, (17) Partnerships for the Goals.

\section{Remediation Techniques}

Remediation is the process of returning soil, water or air functionality that existed prior to contamination. Variety of techniques exist for remediation depending on the media (e.g. air, water, or soil) and contaminant (e.g. heavy metals, PCB etc.) [32]. This could be by physical/mechanical, chemical or biochemical remediation method [33,34]. Remediation strategies are decided after knowing the oil composition and physicochemical nature of the polluted site. Physical and chemical properties and $\mathrm{pH}$ of the polluted water/soil are the different factors on which the crude oil degradation depends.

\section{Physical/mechanical remediation approach}

While physical method principally involves soil replacement and thermal desorption, the method is labor intensive, expensive and suitable for small contaminated sites [35]. This implies it could be unsuitable for large-scale contamination.

An illustration of this is the Capping method, in which a contaminated sediment bed is isolated with a clean layer or "cap" commonly consisting of sand, gravel, silt or crushed rock debris, is also a physical remediation method. The passive cap made of unreactive materials mainly rely on containment rather than treatment. The cap cut down bio availability of contaminants by physically separating sediments from the aquatic environment, confining bioturbation to the top clean layer and limiting the possibility of re-suspension of contaminated sediments [35]. This method and other physical remediation methods, on stand-alone basis, are not suitable for the large-scale contamination. 


\section{Chemical remediation approach}

Chemical method involves washing contaminated soil using clean water, reagents, and solvents that can leach the contaminants from the oil $[33,34]$. These chemicals have the capability of altering the contaminant's chemical and physical properties. This method could be achieved through chemical leaching, chemical fixation, electrokinetic remediation, vitrify technology, chemical immobilisation, oxidation, chemical fluid extraction and photodegradation among others. The method is expensive and has the potential to contaminate other environmental media including air and water bodies through the introduction of solvents and reagents during remediation [34]. Specifically, the approach is fast at clean-up of contaminants, however, harmful wastes generated in the process include carbon dioxide and other greenhouse gases which are emitted into the surrounding environment [36]. The method is expensive and has the potential to contaminate other environmental media including air and water bodies through the introduction of solvent and reagents during remediation [34].

Dispersants, solidifiers, and chemical oxidants are the three categories in which the chemical remediations are grouped [16,37].

\section{Dispersants}

Slick of oil can be broken down into smaller droplets by surfactants which are present in dispersants, and these droplets undergo rapid dilution by transferring it into the water and can be effortlessly degraded [81]. Chemical dispersants can raise the oil droplet surface area which results in an increased rate of natural biodegradation, and this process makes the oil less sticky to the surface by slowing down the development of oil-water emulsions and allows fast treatment [39]. This method makes oil spills less harmful for living organisms and the marine life. This is achieved by converting oil slicks into droplets which in turn can be degraded by bacteria [16,38]. Nokomis 3-F4, Slickgone NS, Finasol OSR 52, SPC 1000M, Neon AB3000, ZI-400, Corexit 9500, Corexit 8667, and Saf-Ron Gold are some of the examples of chemical dispersants [40].

\section{Solidifiers}

In this method oil is removed by physical method which involves the interaction of dry granular materials with the oil and converts its liquid state into rubberlike solid state. Dry particulate and semisolid substances such as balls, pucks, sponge, etc. are the various forms in which the solidifiers can be applied. Solidification can be enhanced by using the solidifiers in the seas because mixing energy is provided by the seawater. Solidifiers are 
difficult to recover after solidification and it is less efficient, which are the major drawbacks for the use of the solidifiers [39].

\section{Chemical oxidation}

This technique involves the usage of chemical agents which are capable of oxidizing the organic pollutants [41]. These chemical agents are introduced by the help of the mixing apparatus and injection in water or soil at the contaminated site. The usefulness of the process is found to depend upon oxidant quality, efficient contact between pollutant and oxidant, geological conditions, and oxidant's residence time [42]. This process is rapid and can be applied in all-weather situations which are some of the advantages of this process.

\section{Biological Remediation approach}

\section{Biological remediation approach (e.g. Phytoremediation and Bioremediation) Phytoremediation}

The biological methods (e.g. bioremediation and phytoremediation) have become of great research interest in the last decade due to their various advantages.

Phytoremediation involves the use of living green plants or their roots to fix or absorb contaminants from soil. This approach uses enzymes present in plant roots to aid degradation of contaminants. It reduces contaminant concentration in soil and consequently reduces risk posed by such contaminants to the environment and human health. For example, [43] used Mirabilis jalapa L. to remove $63.2 \%$ of petroleum from contaminated soil. Phytoremediation has five approaches which include phytostabilisation, phyto-volatilisation, phyto-extraction, phytodegradation and rhizodegradation [44,33]. Phyto-stabilisation is the use of plant roots to absorb and precipitate contaminants thereby fixing them to a point and reducing their bioavailability and migration to other ecological systems such as food chain and underground water [34]. Phytovolatilisation is the transfer of contaminants (e.g. mercury) to a gaseous state by the use of special matters secreted by plant roots. Phyto-extraction on the other hand involves the use of tolerant and accumulating plants to absorb contaminants from soil, which are transferred and stored in over-ground parts [34]. The breakdown of contaminants through the metabolic processes of the plant is described as phytodegradation. Plant roots in such cases release catalytic enzymes such as dehalogenase and laccase, to accelerate the contaminant breakdown process [33]. Rhizodegradation entails the degradation of contaminants through enhanced microbial 
activity in the rhizosphere zone $(1-5 \mathrm{~mm})$ of the soil. In this case, soil microbes benefit the soil by supplying the needed nutrients such as vitamins and amino acids to increase plant growth, while the plant roots provide habitat for microbes that degrade hydrocarbons [33]. Generally, the different approaches of phytoremediation have peculiar characteristics that make them appropriate for different soil contaminants. For example, phytovolatilisation is only appropriate for compounds with volatilisable properties. Phytoremediation provides an approach that allows for low maintenance cost, easily implemented on-site and in areas that generally support plant growth. However, specific phytoremediation prescription could not be applicable to diverse site conditions, as concentration levels could be toxic to the intervention plants [45]. Phytoremediation is a slow remediation strategy and could only be considered for long-term clean-up. In addition, the approach is affected by external parameters which include type and concentration of contaminants, water content, soil chemical properties and plant resistance to phototoxic effects [33], and prevailing ecological and climatic conditions.

Bioremediation is a cost-efficient method used for the treatment of soil polluted with oil and wastes of petroleum consisting of biodegradable hydrocarbons and indigenous microbes. The management of suitable levels of nutrient fertilizer addition, moisture control to optimize soil degradation by microorganisms, aeration and mixing, and $\mathrm{pH}$ amendment are required for the process of land treatment [46]. Enzymes attack on some inorganic compounds and on most of the organic compounds through the activities of living organisms. Bioremediation is the technique which involves the productive use of the biodegradative process for the elimination or detoxification of pollutants from the environment. Oil spill causes contamination of soil which is considered as the chief worldwide concern [3]. Pollution of soil due to petroleum causes a serious effect to human being, affects the groundwater, decreases the agricultural production of the soil, and causes economic loss and ecological problems. Plants, animals, microorganisms, and humans are affected by the toxicity of the petroleum hydrocarbons. Oil spill and accidents occur due to the transportation of crude oil which is generally through tankers on water or through land pipeline.

Certain microorganisms are accountable for the petroleum hydrocarbon degradation and are used as the resource of carbon and energy for growth and maintenance [3]. Soil contamination can be remediated by many ways including both physicochemical and biological techniques. Biological techniques are more economical and proficient than physicochemical techniques. The degradation rate of petroleum products is increased by developing several remediation methods. Bioremediation through microorganism is 
considered to be the most effective method in comparison to other biological methods, but the high molecular weight hydrocarbons with low adsorption and solubility limit their accessibility to microorganisms [3].

The technique was developed in the 1940s and has since been tested on different spill sites. For example, in 1994, the effectiveness of a biosurfactant called PES-51 for the removal of weathered crude from contaminated sand was investigated in Exxon Valdaz oil spill in La Touche Island. The results indicated $70 \%$ of the semivolatile components was removed from the sample [47]. Usually, the biological methods are environmentally friendly and retain the quality of environments (soil or water) during the remediation process. Besides, these methods are cheaper than physical and chemical techniques used for remediation.

Three distinctive approaches are adopted in the context of bioremediation, namely, bioaugmentation, biostimulation and bioventilation.

Bioaugmentation is used to enhance the performance of the microbial population through the addition of bacterial with specific catabolic activities, strains or enrichment consortia to increase the rate of contaminant degradation [33]. One challenge of this approach is that there is no single strain of bacteria that has the requisite metabolic capacity to degrade all oil components. Thus, studies recommend diverse types of bacteria strains and fungi for the remediation of hydrocarbon contaminants [33].

The adjustment of environmental parameters such as nutrient introduction, biopolymers and biosurfactants is described as biostimulation [48]. The adjustment of these parameters could stimulate the growth of oil degrading microbes and thus the rate of responsive degradation by the microbes. The influence of nutrient amendments had been demonstrated [49].

Bioventilation on the other hand involves the addition of oxygen to the soil voids to stimulate the growth of microbes. Oxygen is a necessity and often the limiting factor in the process of biodegradation as it enhances microbial metabolism of organic matter and generate more energy [33]. Bioventing has been shown to be effective and efficient in the remediation of a blend of diesel and biodiesel fuel with a higher remediation rate compared to natural attenuation [50]. They reported $85 \%$ contaminant degradation efficiency compared to $64 \%$ observed in natural attenuation after 60 days.

Generally, bioremediation has been researched extensively with success in hydrocarbon removal from soil in laboratories and a field [33]. Bioremediation has been 
shown to degrade oil contaminants permanently and successfully and leaves little or no adverse effects on the environment. It is also cost effective and eliminates wastes safely without threatening the wider environment [33]. However, bioremediation requires longer treatment durations (up to several years) to achieve satisfactory contaminant removal.

\section{Principle of bioremediation}

Composite mixture of diverse chemical substances makes up the crude oil. Oil and its component are recognized by microbes using bioemulsifiers and biosurfactants and then they join themselves; hydrocarbon is used as the resource of carbon and energy [3]. High molecular weight hydrocarbons due to their low adsorption and solubility limit their accessibility to microorganisms. Oil biodegradation rates are improved by the biosurfactant's addition which increases the elimination and solubility of these pollutants. The oil constituents vary particularly in susceptibility, volatility, and volubility to biodegradation. A number of substances are easily degraded, some are non-biodegradable and some oppose degradation. Diverse species of microbes preferentially attack diverse compounds due to this biodegradation of petroleum that occurs at different rates but concurrently. Enzymes produced by microorganisms in the presence of sources of carbon are accountable for attacking the hydrocarbon molecules. Hydrocarbon present in the petroleum is degraded by different enzymes and metabolic pathways. Hydrocarbon degradation is prevented by the lack of suitable enzyme [51]. Bioremediation process involves the utilization of natural microorganisms for the decontamination of atmosphere [52]. This process converts pollutants into useful or nontoxic substances by using bacteria, fungi, and yeast which are the naturally occurring microorganisms [27]. This is also a process in which microorganisms restore the quality of the environment by degrading and metabolizing the chemical substances [37].

\section{Application of bioremediation}

1. Ecologically sound, natural process; there is an increase in the number of the existing microorganisms when the contaminants are present, and the microbial population decreases naturally when the contaminants are degraded. The residues such as water, carbon dioxide, and fatty acids obtained as a result of the biological treatment are usually non-hazardous product, and the obtained $\mathrm{CO}_{2}$ can be used for the photosynthesis process by the plants. 
2. Bioremediation is responsible for destroying the target chemicals in place of transferring the contaminants from one place to another.

3. Other techniques which are used for the cleanup of harmful waste are costlier than bioremediation. For example, through the cleanup of the Exxon Valdez spill, the cost of 1-day physical washing is more than bio remediating $120 \mathrm{~km}$ of shoreline.

4. Bioremediation deals with in situ treatment and does not involve the transfer of a large amount of the polluted wastes off-site, and the risk due to the transportation can be overcome.

5. Microbe efficiency can be enhanced by using nutrient formulation in the bioremediation process.

Hydrocarbons due to their different solubility from polar compounds such as methanol have lower polarity and hence have low solubility. Degradation of hydrocarbons is not only determined by solubilization. Many microorganisms are responsible for increasing the surface area of the substrate by excreting emulsifiers including Bacillus licheniformis, Pseudomonas putida, Bacillus cereus, Pseudomonas aeruginosa, Bacillus subtilis, and Bacillus laterosporus. Absorption of hydrophobic substance is facilitated by change in the cell surface by microorganisms. The behavior of individual hydrocarbons as well as mixtures can be changed by changing the physicochemical character of hydrocarbons [53].

\section{Conclusion}

Hydrocarbon pollutants have a widely applicable consequence on land, aquatic, as well as atmospheric ecosystem. This has been a problem ever since the use of fossil fuels and industrial revolution started. The unparalleled growth in populations with frequent oil spills, leakages in pipelines, and rampant use of pesticides contribute to substantial increase in pollution. These together are threatening the lives of animals and native microbiological population in land, air, and water surfaces and subsurfaces. Thus environmental remediation is the most important aspect of human survival. Studies and researches taking into consideration the limitations and advantages, indicate that bioremediation is the most suitable technology for the clean-up. This is considered because of the cost of remediation, acceptability, environment friendliness of the technology.

You cannot end poverty in an area where people means of lively hood and revenue 
earning is severely destroyed. Healthy lives and well-being cannot also be achieved in area where the only source of drinking water is significantly polluted; rivers and ponds fishes are contaminated. It is cheap, effective, efficient ecofriendly, requires just inexpensive equipment, has high public acceptability and therefore it is a strategic and sustainable technique for the achievement of the Sustainable Development Goals most especially in low-income countries.

\section{References}

[1] Ite, A.E., Ibok, U.J., Ite, M.U., \& Petters, S.W. (2013). Petroleum exploration and production: past and present environmental issues in the Nigeria's Niger delta. American Journal of Environmental Protection, 1(4), 78-90. https://doi.org/10.12691/env-1-4-2

[2] Obida, C.B., Alan Blackburn, G., Duncan Whyatt, J., \& Semple, K.T. (2018). Quantifying the exposure of humans and the environment to oil pollution in the Niger delta using advanced geostatistical techniques. Environment International, 111, 32-42. https://doi.org/10.1016/j.envint.2017.11.009

[3] Srivastava, M., Srivastava, A., Yadav, A., \& Rawat, V. (2019). Source and control of hydrocarbon pollution, Hydrocarbon Pollution and its Effect on the Environment, Muharrem Ince and Olcay Kaplan Ince, IntechOpen. Available from: https://www.intechopen.com/chapters/67349

https://doi.org/10.5772/intechopen.86487.

[4] Vergetis, E. (2002). Oil Pollution in Greek Seas and Spill Confrontation Means-Methods. Greece: National Technical University of Athens.

[5] Readman, J.W., Fillmann, G., Tolosa, I., Bartocci, J., Villeneuve, J.P., Catinni, C., et al. (2002). PAH contamination of the Black Sea. Marine Pollution Bulletin, 44, 48-62. https://doi.org/10.1016/S0025-326X(01)00189-8

[6] Kim, G.B., Maruya, K.A., Lee, R.F., Lee, J.H., Koh, C.H., \& Tanabe, S. (1999). Distribution and sources of polycyclic aromatic hydrocarbons in sediments from Gyeonggi Bay, Korea. Marine Pollution Bulletin, 38, 7-15.

https://doi.org/10.1016/S0025-326X(99)80006-X

[7] US-EPA Great Lakes National Program Office (1998). Realizing Remediation: A Summary of Contaminated Sediment Remediation Activities in the Great Lakes Basin.

[8] Readman, J.W., Mantoura, R.F.C., Rhead, M.M., \& Brown, L. (1982). Aquatic distribution and heterotrophic degradation of polycyclic aromatic hydrocarbons (PAH) in the Tamar estuary. Estuarine, Coastal and Shelf Science, 14, 369-389.

https://doi.org/10.1016/S0272-7714(82)80009-7 
[9] Meagher, R.B. (2000). Phytoremediation of toxic elemental and organic pollutants. Current Opinion in Plant Biology, 3, 153-162. https://doi.org/10.1016/S1369-5266(99)00054-0

[10] NRC National Research Council (1979). Polychlorinated Biphenyls.

[11] Scragg, A. (2005). Bioremediation, Environmental Biotechnology, 173-229

[12] Uchimiya, M., \& Masunaga, S. (2007). Time trend in sources and dechlorination pathways of dioxins in agrochemically contaminated sediments. Environmental Science and Technology, 41, 2703-2710. https://doi.org/10.1021/es0627444

[13] Kaiser, J. (2000). Just how bad is dioxin?. Science, 288, 1941-1944. https://doi.org/10.1126/science.288.5473.1941b

[14] Dixit, R., Wasiullah, E., Malaviya, D., Pandiyan, K., Singh, U., Sahu, A., et al. (2015). Bioremediation of heavy metals from soil and aquatic environment: An overview of principles and criteria of fundamental processes. Sustainability, 7(2), 2189-2212. https://doi.org/10.3390/su7022189

[15] Das, N., \& Chandran, P. (2011). Microbial degradation of petroleum hydrocarbon contaminants: An overview. Biotechnology Research International, 1-13. https://doi.org/10.4061/2011/941810

[16] Abha, S., \& Singh, C.S. (2012). Hydrocarbon pollution: Effects on living organisms, remediation of contaminated environments and effects of heavy metals co-contamination on bioremediation. In: Romero-Zeron L, editor. Introduction to Enhanced Oil on Recovery (EOR) Processes and Bioremediation of Oil Contaminated Sites. China: InTech Publisher, pp. 186-206. https://doi.org/10.5772/48014

[17] Ward, N., Clark, J., Lowe, P., \& Seymour, S. (1993). Water Pollution from Agricultural Pesticides. Centre for Rural Economy Research Report. Newcastle upon Tyne: Centre for Rural Economy.

[18] FWR. What is Pollution? Foundation for Water Research. 2008. Available from: http://www.euwfd.com/html/source_of_pollution_-_overview.html

[19] Van Metre, P.C., Mahler, B.J., \& Furlong, E.T. (2000). Urban sprawl leaves its PAH signature. Environmental Science \& Technology, 34, 4064-4070. https://doi.org/10.1021/es991007n

[20] Osuji, L.C., \& Nwoye, I. (2007). An appraisal of the impact of petroleum hydrocarbons on soil fertility: The Owaza experience. African Journal of Agricultural Research, 2, 318-324.

[21] Ordinioha, B., \& Brisibe, S. (2013). The human health implications of crude oil spills in 
the Niger delta, Nigeria: An interpretation of published studies. Nigerian Medical Journal, 54, 10-16. https://doi.org/10.4103/0300-1652.108887

[22] Emmanuel, I.O., Gordon, O.D., \& Nkem, A.F. (2006). The effect of oil spillage on crop yield and farm income in Delta state, Nigeria. Journal of Central European Agriculture, 7, 41-48.

[23] Abii, T.A., \& Nwosu, P.C. (2009). The effect of oil-spillage on the soil of eleme in Rivers state of the Niger-Delta area of Nigeria. Research Journal of Environmental Sciences, 3, 316-320. https://doi.org/10.3923/rjes.2009.316.320

[24] Henry, J.G., \& Heinke, G.W. (2005). Environmental Science and Engineering (2nd ed., pp. 64-84). New Delhi, India: Prentice Hall.

[25] Edema, N.E., Obadoni, B.O., Erheni, H., \& Osakwuni, U.E. (2009). Eco-phytochemical studies of plants in a crude oil polluted terrestrial habitat located at Iwhrekan, Ughelli north local government area of Delta state. Natural Science, 7, 49-52.

[26] Gibson, D.T., \& Parales, E.R. (2000). Aromatic hydrocarbon dioxygenases in environmental biotechnology. Current Opinion in Biotechnology, 11, 236-243. https://doi.org/10.1016/S0958-1669(00)00090-2

[27] Mbhele, P.P. (2007). Remediation of Soil and Water Contaminated by Heavy Metals and Hydrocarbons Using Silica Encapsulation. Johannesburg: University of Witwatersrand.

[28] Alonso-Alvarez, C., Perez, C., \& Velando, A. (2007). Effects of acute exposure to heavy fuel oil from the prestige spill on a seabird. Aquatic Toxicology, 84, 103-110. https://doi.org/10.1016/j.aquatox.2007.06.004

[29] Nwilo, P.C., \& Badejo, O.T. (2005). Oil spill problems and management in the Niger Delta. International Oil Spill Conference Proceedings, 567-570.

https://doi.org/10.7901/2169-3358-2005-1-567

[30] Tamuno, S., \& Felix, J.M. (2006). Crude Oil Resource: A Blessing or Curse to Nigeria The Case of the Niger Delta. J. Res. Natl. Dev., 4, 53-58.

https://doi.org/10.4314/jorind.v4i2.42332

[31] African Vault. Top 20 Oil Producing Countries in Africa. Available online: http://www.africanvault.com/oil-producing-countries-in-africa/ (accessed on 13 December 2016).

[32] Gomes, H.I., Dias-Ferreira, C., \& Ribeiro, A.B. (2013). Overview of in situ and ex situ remediation technologies for PCB-contaminated soils and sediments and obstacles for full-scale application. Sci. Total Environ., 445-446, 237-260.

https://doi.org/10.1016/j.scitotenv.2012.11.098 
[33] Lim, M.W., Lau, E. Von, \& Poh, P.E. (2016). A comprehensive guide of remediation technologies for oil contaminated soil — Present works and future directions. Mar. Pollut. Bull., 109, 14-45. https://doi.org/10.1016/j.marpolbul.2016.04.023

[34] Yao, Z., Li, J., Xie, H., \& Yu, C. (2012). Review on remediation technologies of soil contaminated by heavy metals. Procedia Environ. Sci., 16, 722-729.

https://doi.org/10.1016/j.proenv.2012.10.099

[35] Khan, F.I., Husain, T., \& Hejazi, R. (2004). An overview and analysis of site remediation technologies. J. Environ. Manag., 71, 95-122.

https://doi.org/10.1016/j.jenvman.2004.02.003

[36] Cappuyns, V. (2013). Environmental impacts of soil remediation activities: quantitative and qualitative tools applied on three case studies. J. Clean. Prod., 52, 145-154. https://doi.org/10.1016/j.jclepro.2013.03.023

[37] Dave, D., \& Ghaly, A.E. (2011). Remediation technologies for marine oil spills: A critical review and comparative analysis. American Journal of Environmental Sciences, 7, 423-440. https://doi.org/10.3844/ajessp.2011.423.440

[38] Lessard, R.R., \& DeMarco, G. (2000). The significance of oil spill dispersants. Spill Science and Technology Bulletin, 6, 59-68.

https://doi.org/10.1016/S1353-2561(99)00061-4

[39] Nomack, M., \& Cleveland, C.J. (2010). Oil Spill Control Technologies. The Encyclopedia of Earth. Available from: http://www.eoearth.org/view/ article/158385/

[40] USEPA (2011). National Contingency Plan Product Schedule. Washington, DC: US Environmental Protection Agency. Available from http://ocean.floridamarine.org/acp/SJACP/Documents/EPA/NCP_Product_Schedule_ July_2011.pdf

[41] Watts, R., Udell, M., Rauch, P., \& Leung, S. (1990). Treatment of pentachlorophenol contaminated soils using Fenton's reagent. Hazardous Waste \& Hazardous Materials, 7 , 335-345. https://doi.org/10.1089/hwm.1990.7.335

[42] Karpenko, O., Lubenets, V., Karpenko, E., \& Novikov, V. (2008). Chemical oxidants for remediation of contaminated soil and water. A review. Chemistry \& Chemical Technology, 3, 41-45. https://doi.org/10.23939/chcht03.01.041

[43] Peng, S., Zhou, Q., Cai, Z., \& Zhang, Z. (2009). Phytoremediation of petroleum contaminated soils by Mirabilis Jalapa L. in a greenhouse plot experiment. J. Hazard. Mater. 168, 1490-1496. https://doi.org/10.1016/j.jhazmat.2009.03.036

[44] Wang, J.-Z., Zhang, G.-H., Mu, H.-D., \& Yan, M.-J. (2011). Quantitative valuation and 
validation of the influence degree of human activities on shallow groundwater. Shuili Xuebao (J. Hydraul. Eng.), 42, 1445-1451.12

[45] Susarla, S., Medina, V.F., \& McCutcheon, S.C. (2002). Phytoremediation: an ecological solution to organic chemical contamination. Ecol. Eng., 18, 647-658.

https://doi.org/10.1016/S0925-8574(02)00026-5

[46] Salanitro, J.P., Dorn, P.B., Huesemann, M.H., Moore, K.O., Rhodes, I.A., Ricejackson, L.M., et al. (1997). Crude oil hydrocarbon bioremediation and soil ecotoxicity assessment. Environmental Science and Technology, 31, 1769-1776.

https://doi.org/10.1021/es960793i

[47] Tumeo, M., Braddock, J., Venator, T., Rog, S., \& Owens, D. (1994). Effectiveness of a biosurfactant in removing weathered crude oil from subsurface beach material. Spill Sci. Technol. Bull., 1, 53-59. https://doi.org/10.1016/1353-2561(94)90007-8

[48] Jiang, Y., Brassington, K.J., Prpich, G., Paton, G.I., Semple, K.T., Pollard, S.J.T., \& Coulon, F. (2016). Insights into the biodegradation of weathered hydrocarbons in contaminated soils by bioaugmentation and nutrient stimulation. Chemosphere, 161, 300307. https://doi.org/10.1016/j.chemosphere.2016.07.032

[49] Chaîneau, C.H., Rougeux, G., Yéprémian, C., \& Oudot, J. (2005). Effects of nutrient concentration on the biodegradation of crude oil and associated microbial populations in the soil. Soil Biol. Biochem., 37, 1490-1497. https://doi.org/10.1016/j.soilbio.2005.01.012

[50] Thomé, A., Reginatto, C., Cecchin, I., \& Colla, L.M. (2014). Bioventing in a residual clayey soil contaminated with a blend of biodiesel and diesel oil. J. Environ. Eng., 140, 1-6. https://doi.org/10.1061/(ASCE)EE.1943-7870.0000863

[51] Thapa, B., KC, A.K., \& Ghimire, A. (2012). A review on bioremediation of petroleum hydrocarbon contaminants in soil. Kathmandu University Journal of Science, Engineering and Technology, 8(1), 164-170. https://doi.org/10.3126/kuset.v8i1.6056

[52] Sharma, S. (2012). Bioremediation: Features, strategies and applications. Asian Journal of Pharmacy and Life Science, 2, 202-213. https://doi.org/10.3126/kuset.v8i1.6056

[53] Patel, V., \& Shah, K. (2014). Petroleum hydrocarbon pollution and its biodegradation. International Journal of Chemtech Applications, 2, 63-80. 